\title{
More, better, faster
}

\author{
Bo Söderström
}

The indicators for measuring the performance of Ambio- $A$ Journal of Human Environment all show positive trends. The journal impact factor continued its upward trend and reached 3.69 for 2016 (Fig. 1a). Even more encouraging is that Ambio is reaching more readers every year: the number of full-text downloads of Ambio articles per year has an almost exponential increase (Fig. 1b). In 2018, we will likely surpass more than 1 million downloads. Furthermore, the number of submissions has doubled since I started as editor-in-chief in 2010 (Fig. 1c). Besides an increase in number, we also experience an increase in the scientific quality of submissions.

Ambio is truly an international journal and this is something we take great pride in. While there is a predominance of authors from Europe and North America, we also have a fair representation from at least two other continents in most regular issues (as shown by corresponding author country of origin). Ambio was one of the first scientific journals to introduce a double-blind review system in which both authors and reviewers are anonymous throughout the review process. We have received only positive feedback to this change implemented more than 5 years ago (Söderström 2012), and we will therefore continue with double-blind review as one way of trying to secure a non-biased treatment of submitted papers regardless of author's name, gender, institution, etc.

An important factor contributing to this positive development is open access publication. Almost every second article in Ambio is published freely accessible, which is partly made possible by the Springer Compact agreement where researchers from participating institutions can publish open access articles at no extra charge. ${ }^{1}$ Even if articles are not published open access, a full-text version of the article can immediately be shared for free by authors or journal

\footnotetext{
${ }^{1}$ Read more: http://www.springer.com/gp/open-access/springeropen-choice/springer-compact.
}

subscribers to colleagues via the SharedIt-initiative, ${ }^{2}$ and after the 12-month embargo period all articles are available for free via PubMed Central. ${ }^{3}$ All these initiatives have been made possible by the excellent cooperation between the Royal Swedish Academy of Sciences and Springer Nature.

As a consequence of this development, we now need to prepare for publishing more articles per year. Starting in 2019, we will publish Ambio monthly to meet the growing interest in publishing in one of the world's leading environmental journals. Ambio published six issues per year between 1972 and 1988 and eight issues per year from 1989 to 2018 . We anticipate that a further benefit from publishing monthly issues will be a decreased time interval between online publication of a manuscript (about 3 weeks after final acceptance) and its assignment of issue and page numbers.

We will continue to publish two to four special issues per year but—also from 2019-open access will no longer be mandatory for articles published in special issues. We therefore foresee that each special issue will contain a mix of open- and paid-access articles. The lack of ability to pay publication fees should not preclude authors from submitting their best work to Ambio's special issues. To make the work of guest editors easier and to permanently archive reviewer reports, we will use our Editorial Manager system for submission and peer review work. ${ }^{4}$ If you are interested in submitting a proposal for a special issue, please plan 12-18 months ahead due to the intense competition for publication space in Ambio. Further information can be found on our website ${ }^{5}$ or be gained by sending me an e-mail.

\footnotetext{
${ }^{2}$ Read more: https://www.springernature.com/gp/researchers/sharedit.

3 Download: http://europepmc.org/journals/1878/.

${ }^{4}$ http://www.editorialmanager.com/ambi/default.aspx.

5 http://www.springer.com/environment/journal/13280.
} 
(a) Journal Impact Factor

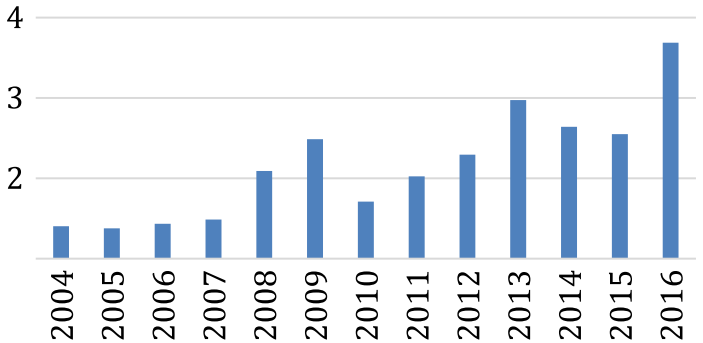

(b)
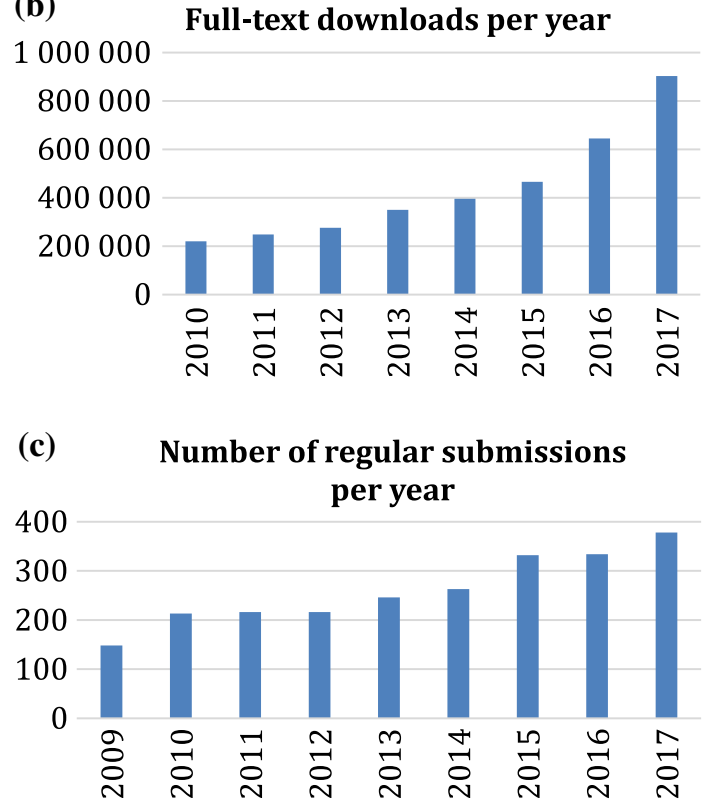

Fig. 1 Ambio performance indicators as shown by a journal impact factor, $\mathbf{b}$ number of full-text downloads per year (data from Springer Link, Europe PMC, JSTOR and BioOne), and $\mathbf{c}$ number of regular submissions (i.e. excluding submissions for special issues) per year
The upcoming special issues of 2019 showcase exciting results of truly international co-operations among researchers in different disciplines with case studies spread across the globe. The first special issue deals with what we know, and still need to find out, about how humans can adapt to climate-driven changes in biodiversity and ecosystem services, while the second special issue covers urban transformative capacity and how we enable systemic change for sustainability in and through cities. Most Ambio readers are familiar with our long-standing tradition of publishing special issues from the Arctic and Baltic Sea geographical regions. Naturally we will continue to publish topical multi- or interdisciplinary research from these regions, which are facing increasing environmental challenges due to climate change, over-fertilization, etc.

As always I am very keen to hear from you if you have any comments or suggestions on how to develop the journal further. Do feel free to also send me and my editorial team words of encouragement or things that you particularly like about Ambio. I look forward to hearing from you by e-mail!

\section{REFERENCE}

Söderström, B. 2012. Increasing access to your research published in Ambio. 41: 325-326. https://doi.org/10.1007/s13280-012-02932.

\section{AUTHOR BIOGRAPHY}

Bo Söderström $(\square)$ Editor-in-Chief Ambio - A Journal of the Human Environment

Address: The Royal Swedish Academy of Sciences, Box 50005, 10405 Stockholm, Sweden.

e-mail: bo.soderstrom@kva.se 